\title{
Colaboração Profissional Docente em um Estudo de Aula no Contexto Brasileiro
}

\author{
Teacher Professional Collaboration in a Lesson Study in the Brazilian Context
}

\author{
Adriana Richit*a; Ana Paula Tomasia; Marisol Vieira Meloa
}

${ }^{a}$ Universidade Federal da Fronteira Sul. RS, Brasil.

*E-mail: adriana.richit@uffs.edu.br

\begin{abstract}
Resumo
O desenvolvimento profissional abarca distintas dimensões, entre elas a colaboração, que oportuniza aos professores partilhar ideias, valores, experiências e refletir sobre a prática profissional. Uma abordagem de desenvolvimento profissional baseada na colaboração é o estudo de aula (lesson study). Nesta perspectiva, realizamos uma investigação visando evidenciar e compreender os aspectos da colaboração profissional vivenciados por um grupo de oito professores de matemática dos anos finais do ensino fundamental, participantes em um estudo de aula. O estudo de aula foi desenvolvido de agosto a dezembro de 2019, estruturado em 12 encontros quinzenais de 2,5 horas cada, e envolveu professores de escolas públicas estaduais pertencentes a $15^{\text {a }}$ Coordenadoria Regional de Educação do Rio Grande do Sul, Brasil. O material empírico constituiu-se dos registros produzidos nos encontros, transcrição das gravações de áudio das sessões do estudo de aula, bem como das notas de campo produzidas na aula de investigação (terceira etapa do estudo de aula). A análise, qualitativa e interpretativa, evidenciou três aspectos da colaboração profissional: apoio e incentivo mútuo, partilha e diálogo. O apoio e incentivo mútuo foram muito valorizados pelos professores porque criaram as condições para que todos pudessem participar do processo e se envolvessem em todas as etapas. A partilha oportunizou aos professores partilhar expectativas, angústias, objetivos e experiências de sala de aula. O diálogo os oportunizou experimentar um processo formativo que valorizava a voz dos participantes e a negociação de decisões. Esses aspectos, em relação de complementaridade, fortaleceram as ações e interações entre os professores participantes e a confiança entre os pares, favorecendo aprendizagens profissionais relacionadas à docência em matemática.
\end{abstract}

Palavras-chave: Colaboração Profissional. Lesson Study. Estudos de Aula. Desenvolvimento Profissional de Professores. Formação de Professores.

\begin{abstract}
Teacher Professional development encompasses important dimensions, such as collaboration, which gives teachers the opportunity to share ideas, values, experiences, and reflect on professional practice. A collaborative approach to professional development is lesson study. In this perspective, we carried out a research aiming to highlight and understand the aspects of professional collaboration experienced by a group of eight mathematics teachers from the final years of elementary school, participating in a lesson study. The lesson study was carried out from August to December 2019, structured into 12 meetings of 2.5 hours each, and involved teachers from state public schools belonging to the 15th Regional Education Coordination of Rio Grande do Sul, Brazil. The research empirical material consisted of audio recordings produced in the meetings, transcription of audio recordings of the lesson study sessions, as well as researcher field notes produced in the research lesson (third stage of the lesson study). The analysis, qualitative and interpretive, highlighted three aspects of professional collaboration: mutual support and encouragement, sharing, and dialogue. The mutual support and encouragement were highly valued by the teachers because they created the conditions for them to participate in the process and get involved at all stages. The sharing gave the teachers the opportunity to share expectations, anxieties, goals, and classroom experiences. Dialogue gave them the opportunity to experience a teacher education process that valued the voice of the participants and the negotiation of decisions. These aspects, in a complementary relationship, strengthened the actions and interactions between the participating teachers and the trust among peers, favoring professional learning related to mathematics teaching.
\end{abstract}

Keywords: Professional Collaboration. Lesson Study. Teacher Professional Development. Teacher Education.

\section{Introdução}

O desenvolvimento profissional, concebido como fenômeno contínuo e dinâmico pelo qual o professor desenvolve-se pessoal e profissionalmente, transcendendo o nível individual para o coletivo (Richit, 2020), constitui-se em componente central das propostas para melhorar a educação (Hargreaves, 1998, Day, 1999, Guskey, 2002), abrangendo os conhecimentos, as aprendizagens e a cultura profissional (Richit \& Ponte, 2020; Richit, Ponte \& Tomasi, 2021).
Esse processo envolve a formação inicial, as atividades profissionais cotidianas do professor, suas vivências pessoais, suas crenças e disposições, os elementos da cultura profissional, assim como os diversos dispositivos de formação vivenciados ao longo da carreira, promovendo o crescimento pessoal e profissional e fomentando mudanças na prática (Richit \& Ponte, 2019). Nesta direção, apoiados em Christopher Day (1999), Saraiva e Ponte (2003) ressaltam que o professor, ao longo da trajetória profissional, “[...] revê, renova e amplia os 
seus compromissos quanto aos propósitos do ensino e adquire e desenvolve, de forma crítica, o conhecimento, as técnicas e a inteligência (cognitiva e afectiva) essenciais a uma prática profissional de qualidade com os alunos, no contexto escolar" (p.27). Esta concepção circunscreve processos presentes nas culturas profissionais, que influenciam o modo como os profissionais interagem no contexto em que atuam e se relacionam (Richit, Ponte, \& Tomkelski, 2020).

As culturas profissionais, de acordo com Hargreaves (1998), apoiam-se nas relações entre pares, caracterizando "uma perspectiva que põe em relevo aquilo que é possuído e partilhado em comum nas relações humanas: os valores, os hábitos, as normas e as crenças, isto é, o conteúdo partilhado nas culturas dos professores" (p.213). Lima (2002) acrescenta que as culturas profissionais precisam ser compreendidas de modo significativo em termos de crenças, valores, comportamentos e práticas, que contemplem o "fazer e agir", assim como o "sentir e pensar".

Assim concebida, a cultura profissional é responsável por embasar as ações coletivas, que são organizadas nos estabelecimentos de ensino (Thurler, 2001). Neste contexto, tomam lugar importantes formas de cultura profissional, em especial a colaboração, que se refere ao princípio cooperativo da associação entre professores em formas administrativamente reguladas e previsíveis de agir (Hargreaves, 1998). A colaboração baseia-se no diálogo e na ação entre pares, nas decisões partilhadas e no apoio mútuo (Hargreaves, 1998), mediante a qual os professores são encorajados a diversificar as estratégias de ensino, correr riscos, propor mudanças e refletir sobre a prática.

A colaboração promove o crescimento profissional e assegura a mudança educacional (Hargreaves, 1998), pois “a colaboração não se justifica por si própria: ela é um meio para se atingir um fim mais nobre: a aprendizagem mais rica e mais significativa dos alunos" (Lima, 2002, p.8). Portanto, a colaboração profissional, devido as suas características e possibilidades de favorecer o desenvolvimento profissional de professores, tem sido evidenciada em distintas abordagens de formação docente.

Um dispositivo de formação baseado na colaboração é o estudo de aula, que consiste em uma abordagem de desenvolvimento profissional centrada na prática letiva e de natureza reflexiva e colaborativa (Murata, 2011; Richit, Ponte \& Tomkelski, 2019). O estudo de aula pode "proporcionar oportunidades para os professores participantes aprofundarem os seus conhecimentos e refletirem sobre a eventual pertinência de mudarem as suas práticas" (Ponte, Quaresma, Mata-Pereira \& Baptista, 2014, p. 61). Esta abordagem apresenta possibilidades e desafios, os quais têm sido foco de pesquisas em vários países. No Brasil, a disseminação dos estudos de aula é recente, embora pesquisadores de todas as regiões crescentemente têm se interessado por esta temática.

Considerando a relevância dos temas 'colaboração profissional' e 'estudos de aula' no campo educacional e visando contribuir com as discussões sobre estas temáticas, nossa investigação buscou evidenciar e compreender os aspectos da colaboração profissional, mobilizados no contexto de um estudo de aula. A investigação envolveu oito professores que ensinam matemática nos anos finais do ensino fundamental em escolas pertencentes à $15^{\mathrm{a}}$ Coordenadoria Regional de Educação (CRE), sediada no município de Erechim, Rio Grande do Sul. A pesquisa tem potencial para contribuir na disseminação dos estudos de aula no contexto brasileiro, assim como para a compreensão de aspectos da colaboração que são centrais no estudo de aula e para o desenvolvimento profissional de professores que ensinam Matemática.

\section{Desenvolvimento e Cultura Profissional de Professores}

Diferentes concepções embasam os percursos formativos de professores, nomeadamente aquelas que se referem ao seu desenvolvimento profissional. Ponte (1998) afirma que a formação profissional permanente é uma necessidade que deve ser encarada de modo positivo, pois representa um importante aspecto na profissão docente, além de constituir-se em uma dimensão do desenvolvimento profissional. Odesenvolvimento profissional envolve princípios fundamentais, tais como a constituição de conhecimentos basilares à docência, a realização de aprendizagens profissionais, assimilação e modificação da cultura profissional e mudanças na prática (Richit, 2020).

Nesta direção, Fiorentini (2008, p. 45) caracteriza o desenvolvimento profissional "como um processo contínuo que tem início antes de ingressar na licenciatura, estende-se ao longo de toda sua vida profissional e acontece nos múltiplos espaços e momentos da vida de cada um, envolvendo aspectos pessoais, familiares, institucionais e socioculturais". Assim compreendido, o desenvolvimento oportuniza o crescimento profissional do professor, que lhe permite conduzir o ensino "adaptado às necessidades e interesses de cada aluno e a contribuir para a melhoria das instituições educativas, realizando-se pessoal e profissionalmente" (Ponte, 1998, p. 29).

Para Guskey (2002, p.282), o desenvolvimento profissional constitui-se em uma oportunidade para o professor "expandir seus conhecimentos e habilidades, contribuir para seu crescimento e aumentar a sua eficácia com alunos". Além disso, promove a mudança na prática, que envolve desde o uso de novos materiais didáticos até uma nova forma de organização da sala de aula. Contudo, a mudança bemsucedida ocorre, segundo o autor, de acordo com as atitudes e crenças dos professores, sendo que estas são moldadas pela experiência profissional (Guskey, 2002) e pela cultura profissional.

As culturas profissionais "compreendem as crenças, valores, hábitos e formas assumidas de fazer as coisas 
em comunidade de professores que tiveram de lidar com exigências e constrangimentos semelhantes ao longo de muitos anos" (Hargreaves, 1998, p. 185). Estas culturas atribuem sentido e identidade ao trabalho docente, assim como fornecem apoio pessoal e profissional ao professor. Ainda, fornecem importante contexto para as relações estabelecidas entre pares, contribuindo para o desenvolvimento profissional do professor e melhoria da escola (Hargreaves, 1998).

Monica Thurler compartilha a perspectiva de Andy Hargreaves ao enfatizar que as culturas das instituições educativas caracterizam um processo dinâmico e evolutivo, que é constituído pelos atores, mesmo que, muitas vezes, de forma inconsciente. Segundo ela, a cultura profissional caracteriza

[...] o conjunto de regras do jogo que organiza a cooperação, a comunicação, as relações de poder, a divisão do trabalho, os modos de decisão, as maneiras de agir e interagir, a relação com o tempo, a abertura para fora, o estatuto da diferença e da divergência, a solidariedade (Thurler, 2001, p.90).

Para Lima (2002, p. 51), "as culturas profissionais dos professores representam mais do que simples agregados de conhecimentos e de concepções: elas integram, igualmente, comportamentos e práticas, modos de agir nas escolas e de interagir com os colegas". Hargreaves (1998) propõe uma categorização para as culturas profissionais de professores constituídas de quatro categorias centrais: individualismo, balcanização, colegialidade artificial e colaboração. Dentre estas perspectivas de culturas profissionais, nos aprofundaremos na colaboração, explicitando os aspectos a ela relacionados e as possibilidades de favorecer o desenvolvimento profissional dos professores. Realizamos este recorte por compreendermos que a colaboração profissional oportuniza ao professor concretizar um trabalho conjunto, a partilha de experiências, ideias, informações, decisões, assim como receber e dar apoio nas mais diversas situações (Lima, 2002).

Nas culturas de colaboração, as relações de trabalho entre professores tendem a seguir alguns princípios, fornecendo-lhes subsídios que os levam a refletir sobre a prática profissional. As relações colaborativas baseiam-se, especialmente, nas decisões partilhadas, no diálogo e no apoio mútuo entre pares (Lima, 2002). Por sua vez, Borges (2007) considera que uma "cultura de colaboração profissional é aquela em que tudo, o bom, o mau, a incerteza e a certeza se partilham, são discutidos, em que se procura o apoio e a ajuda necessários para aprender" (p. 370-371). Além disso, os professores não se sentem constrangidos ao partilhar suas dificuldades, por exemplo, pois o sentimento de pertencer a um grupo profissional em que todos exprimem suas dúvidas, partilham angústias e aceitam desafios, os tornam capazes de empenharse no trabalho de forma colaborativa (Borges, 2007).

Em contexto de colaboração, os professores são encorajados a correr riscos, a diversificar suas estratégias de ensino, a enfrentar as mudanças como um processo de aperfeiçoamento contínuo (Ponte, 1998). A colaboração melhora o desempenho docente, uma vez que "promove a reflexão, a aprendizagem profissional e a associação entre as diferentes destrezas, a colaboração é um princípio crucial da aprendizagem organizacional" (Hargreaves, 1998, p.279).

Outro elemento fundamental para a concretização da colaboração é o diálogo. Goulet, Krentz e Chistiansen (2003) destacam a importância de ouvir e valorizar as contribuições de cada membro do grupo, visto que é através de algum tipo de conversa que os envolvidos partilham informações e conselhos. As ideias e conhecimentos partilhados devem ser recebidos e acolhidos abertamente pelo grupo e tratados com respeito. O diálogo, aliado à maneira como os envolvidos são encorajados, desenvolve a confiança, que é essencial para que as vozes individuais sejam externalizadas em grupos que trabalham coletivamente (Goulet, Krentz \& Chistiansen, 2003).

Nóvoa (2009) ressalta que a colaboração favorece avanços no que se refere aos movimentos pedagógicos e a modificação de crenças, valores e conhecimentos. A partir desses movimentos, o sentimento de pertença e de identidade profissional é reforçado, favorecendo o engajamento dos professores em processos de mudança, que em seu conjunto se refletem na cultura profissional, pois tais "movimentos, tantas vezes baseados em redes informais e associativas, são espaços insubstituíveis no desenvolvimento profissional dos professores" (Nóvoa, 2009, p. 41). Para além, segundo Hargreaves (1998, p. 185), a cultura profissional é responsável por transmitir às gerações de professores "soluções historicamente geradas e coletivamente partilhadas de uma comunidade", especialmente sobre os modos de organização e ação profissional.

Além disso, o trabalho em colaboração oportuniza aos professores partilharem angústias e objetivos acerca das dificuldades de aprendizagem dos alunos e, desta forma, refletirem sobre a prática e sobre a necessidade de modificá-la (Richit \& Ponte, 2019). Envolve, também, a interconexão entre aquilo que é "realizado no interior e no exterior da profissão, que obriga a intensas interações e partilhas" (Nóvoa, 1995, p.29).

Assim, os contextos colaborativos, nos quais o professor tem a possibilidade de interagir e partilhar experiências, refletir sobre a prática, sendo também motivado e apoiado pelos pares, favorecem o desenvolvimento profissional do docente (Ponte, 1998). Para tanto, é imprescindível um campo profissional autônomo e aberto, de modo que a colegialidade, a partilha e as práticas colaborativas possam ocorrer de forma espontânea e não impostas administrativamente (Nóvoa, 1995). Nesta perspectiva, as atitudes inovadoras e práticas são transformadas mediante tensões e rupturas nas culturas profissionais de professores, na medida em que as atitudes, crenças, concepções e disposições são influenciadas e modificadas. 


\section{Estudos de Aula}

Os estudos de aula, originários do Japão no início do século $\mathrm{XX}$, consolidaram-se como um dos principais processos de desenvolvimento profissional de professores naquele país (Lewis, 2002). Esta abordagem, que assume natureza reflexiva e colaborativa (Lewis, 2002; Ponte Richit \& Ponte, 2017), se consolidou no sistema educativo japonês, em face à transição do modelo de ensino individualizado para o modelo de ensino mútuo, nas primeiras décadas no século vinte (Richit, 2020).

O estudo de aula é um dispositivo de desenvolvimento profissional que prioriza quatro momentos/etapas centrais (Lewis, 2002), embora a literatura evidencie algumas variações com redução ou acréscimo de etapas. Dentre os modelos predominantes na literatura europeia e norte-americana, adotamos o modelo apresentado em Ponte Quaresma, MataPereira \& Baptista (2014), que se estrutura em cinco etapas bem definidas: definição/formulação de objetivos para uma aula, planejamento da aula, concretização/lecionação da aula, reflexão sobre a aula e seguimento/nova lecionação da aula. Verifica-se que as abordagens concretizadas em Portugal acrescentam uma etapa adicional ao modelo de Lewis (2002), a qual prioriza a reformulação da aula planejada e que pode dar início a um novo ciclo de estudo de aula. Estas cinco etapas estão descritas em Richit, Ponte \& Tomkelski (2019, p.58), da seguinte forma:

$\mathrm{Na}$ definição/formulação de objetivos para a aprendizagem e desenvolvimento dos alunos, seleciona-se um tópico ou tema do currículo para ser abordado na aula de investigação; no planejamento, prepara-se cuidadosamente a aula para alcançar os objetivos definidos; na concretização/ lecionação, a equipe que participa do estudo de aula observa e colhe informações sobre as ações dos alunos durante toda a aula, por meio de notas ou gravações em áudio ou vídeo; $n a$ reflexão, focalizam-se os aspectos relativos à aprendizagem e desenvolvimento dos alunos, observados e registrados na etapa anterior, que podem contribuir para melhorar a aula planejada; e, por último e se desejável, na nova leccionação da aula de investigação, repete-se o processo.

A abordagem dos estudos de aula, por ser fortemente ligada à prática de sala de aula, é concebida como um processo formativo direcionado ao trabalho do professor, que se difere em alguns aspectos das abordagens de formação de professores, tradicionalmente desenvolvidas nos sistemas de ensino (Richit \& Ponte, 2019) pelo fato de envolver observações de aulas e centrar-se na prática letiva, focando a aprendizagem dos alunos e não a atuação docente (Ponte, et al., 2016). Além disso, favorece mudanças no ensino da matemática, contribuindo para o crescimento profissional do professor e para a aprendizagem dos alunos (Puchner \& Taylor, 2006). O estudo de aula, por sua natureza colaborativa, favorece mudanças na prática, potencializando e mobilizando os professores a alcançar um objetivo assumido pelo grupo, e assim, promovendo o seu desenvolvimento profissional (Araujo, Ribeiro \& Fiorentini, 2017).

Ao participar de um estudo de aula, os professores têm a oportunidade de refletir sobre os processos de raciocínio, as dificuldades apresentadas pelos alunos, a dinâmica da sala de aula e sobre modos de promover a discussão coletiva (Richit \& Ponte, 2019, Ponte et al., 2016). É um processo que favorece a articulação entre o conhecimento teórico e o conhecimento oriundo da experiência, mediante o trabalho colaborativo e reflexivo, a partilha de experiências, a preocupação com a prática e a realização de aprendizagens profissionais (Ponte, Quaresma, Mata-Pereira \& Baptista, 2014). Além disso, a oportunidade de planejar a aula de investigação colaborativamente e de observar os alunos é uma mudança valorizada por professores que participam de estudos de aula (Cajkler, Wood, Norton \& Pedder, 2014).

O estudo de aula, pela sua dinâmica em que a colaboração constitui um contexto para favorecer a comunicação entre os participantes e a reflexão sobre a prática profissional, oportuniza ao professor interagir com os colegas, partilhar experiências e materiais de ensino, bem como apoiar e ser apoiado na tomada de decisões (Ponte et al., 2016). A colaboração, portanto, caracteriza a cultura profissional em que os professores constituem um coletivo "de pessoas que interagem, dialogam e refletem em conjunto, criamse sinergias que possibilitam uma capacidade de reflexão acrescida e um aumento das possibilidades de aprendizagem mútua [...]" (Boavida \& Ponte, 2002, p. 45).

Assim concebido, o estudo de aula oportuniza ao professor articular conhecimento teórico e prático, que lhe permite desenvolver um olhar crítico para sua prática, considerando os processos e o modo como essa prática influencia a aprendizagem dos alunos. Promove, também, a autoconfiança, fundamental para a mudança da prática, uma vez que a reflexão sobre a prática o conduz a uma investigação e, em seguida, a transformação (Ponte et al., 2016; Richit \& Ponte, 2017).

Na colaboração entre pares, como ocorre nos estudos de aula, os participantes trabalham para alcançar um mesmo objetivo, promovendo melhores compreensões sobre uma realidade (Richit \& Ponte 2019), pois a diversidade de pontos de vista permeia as estratégias para se chegar a este objetivo comum (Hargreaves, 1998; Boavida \& Ponte, 2002; Tomasi, 2020).

Portanto, a colaboração concretizada em um estudo de aula, concebida como um princípio basilar desta abordagem e que é favorecida pela dinâmica das interações entre os participantes (Puchner \& Taylor, 2006), tem se constituído em um importante mecanismo de desenvolvimento profissional de professores (Murata 2011; Ponte et al., 2016; Richit \& Ponte, 2019). No estudo de aula, os professores têm a oportunidade de experimentar uma forma colaborativa e reflexiva de trabalho profissional, que ultrapassa o individualismo predominante nas práticas docentes.

\section{Metodologia}

A investigação segue uma abordagem qualitativa centrada em um processo interpretativo e analítico, apoiado em 
processos como observações, registros, notas de campo e entrevistas (Denzin \& Lincoln, 2006). A investigação buscou evidenciar e compreender aspectos da colaboração profissional mobilizados em um estudo de aula realizado com professores de matemática dos anos finais do ensino fundamental. Os professores participantes lecionavam em escolas vinculadas à

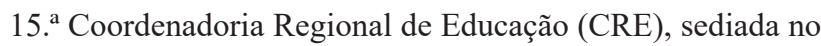
município de Erechim, estado do Rio Grande do Sul, Brasil.

O estudo de aula foi organizado em doze encontros de aproximadamente três horas cada. Após cada encontro foi produzido um relatório detalhado, destacando as problematizações, reflexões, relatos de experiências e atividades desenvolvidas pelos professores. Estas observações e registros constituíram as notas de campo, concebidas como "relatos escritos daquilo que o investigador vê, ouve, experiencia e pensa no decurso da recolha [...]" (Bogdan \& Biklen, 1994, p.150). Após a finalização do estudo de aula, realizamos uma entrevista semiestruturada com os professores participantes. As entrevistas constituem-se em uma importante técnica de recolha de dados em estudos qualitativos, pois "produzem uma riqueza de dados, recheados de palavras que revelam as perspectivas dos respondentes" (Bogdan \& Biklen, 1994, p. 136).

A análise sobre o material empírico evidenciou diversos aspectos intrínsecos à colaboração profissional docente, os quais constituem as três categorias apresentadas neste texto: partilha, diálogo, assim como apoio e incentivo mútuo.

\section{Princípios da Colaboração Evidenciados no Estudo de Aula}

A análise do material empírico, do qual extraímos as evidências empíricas estruturantes das categorias elegidas para discussão, permitiu-nos evidenciar aspectos intrínsecos à colaboração profissional concretizada em um estudo de aula e, especialmente sobre o modo como esses aspectos se concretizam nas interações entre os professores. Assim, dedicamo-nos a apresentar as evidências empíricas, interpretálas na perspectiva de compor e consolidar as categorias de análise focadas neste trabalho e, por fim, discuti-las à luz do referencial teórico da pesquisa. As categorias evidenciadas são: partilha, diálogo, assim como incentivo e apoio mútuo.

Partilha. As narrativas dos professores revelaram que muitos são os desafios enfrentados diariamente no contexto escolar e no ensino em sala de aula. Numa perspectiva contrária ao isolamento predominante na docência, o estudo de aula favoreceu a partilha de experiências pessoais e profissionais, a partilha de angústias e preocupações, fortalecendo as relações entre eles, especialmente por sentirem-se parte de um grupo profissional que se depara com desafios similares e que compartilha objetivos educacionais. Este aspecto foi evidenciado em todas as etapas do estudo de aula, com ênfase na fase de planejamento da aula de investigação.

De acordo com os professores, o estudo de aula favoreceu a partilha de experiências profissionais, sobretudo de estratégias de ensino desenvolvidas em sala de aula, conforme apontam os excertos a seguir:

Eu já falei [hoje], mas deixa eu falar minha experiência essa semana, em que eu fiz a prática com chocolate [para ensinar] fração né. Aí lá na prova eles tinham que justificar o que era o numerador e o denominador e eu falei assim: o que o denominador significa? O que eu comi. Os pedacinhos de chocolate [que eu comi] ( $\mathrm{Judy}^{1}$, transcrição áudio $2^{\mathrm{a}}$ sessão, agosto de 2019).

[...] eles [os alunos] têm tanta dificuldade no entendimento [sobre mínimo múltiplo comum] que eu tinha [na escola] uma maletinha com todo material e o meu estojo. O aluno tinha tanta dificuldade [com o mínimo múltiplo comum] que eu disse [para ele]: pega a minha maletinha e coloca dentro do estojo para [você] ver se consegue. Agora [depois de tentar], tenta colocar o estojo dentro da maletinha. A partir dali [do exemplo prático] ele [o aluno entendeu o conceito], mas ele [o aluno] tinha muita dificuldade. [...] é só decompor e eles [os alunos] não conseguem fazer essa relação (Judy, transcrição áudio $10^{\mathrm{a}}$ sessão, dezembro de 2019).

A professora Judy partilhou algumas estratégias e recursos utilizados para auxiliar os alunos, as quais foram bastante elogiadas pelos pares. Ao partilhar experiências, os professores oportunizam aos colegas aprender um pouco com essas práticas e, assim, experimentá-las com seus alunos, conforme relatado no grupo. Nessa direção, a partilha levou ao despontar da colaboração na medida em que favoreceu o pensar sobre a prática e a apropriação das estratégias e recursos socializados no coletivo. Na perspectiva de partilhar experiências, Adelle relatou uma atividade que ela desenvolveu em sala de aula para trabalhar os tópicos 'área e perímetro' com os alunos do $8^{\circ}$ ano.

Eu fiz [os alunos] medirem com a trena. Calcularam a área, depois eu fiz eles [os alunos] medirem com a linha [utilizando um pedaço de barbante para contornar a área solicitada]. Quando eles somaram, já sabiam a medida dos lados por terem calculado a área. [Com a linha e a trena esticada] eu disse assim [aos alunos]: vocês conseguem esticar a trena para medir o total da área? [Os alunos responderam]: não professora porque temos que multiplicar esse [lado] por esse [lado]. E o perímetro? [...] se a gente pode esticar ele [se referindo ao barbante/linha que representa o perímetro], então quer dizer que ele [perímetro] pode mudar de forma. [...] eles [os alunos] conseguiram ver, conseguir fazer, tirar essa dúvida [a partir do exemplo prático] (Adelle, transcrição áudio $3^{\mathrm{a}}$ sessão, setembro de 2019).

As experiências partilhadas por Judy e Adelle contribuíram para o planejamento da aula de investigação, porque foram tomadas como ponto de partida na elaboração da tarefa exploratória e para a escolha dos materiais a serem utilizados pelos alunos na realização dessa tarefa. Ao final, depois da aula de investigação na referida escola, a partilha das angústias dos professores, das suas inseguranças, se constituiu em um importante momento de fortalecimento e crescimento do 
grupo. Os professores sentiram que compartilhavam o receio de experimentar uma prática de sala de aula diferente (a aula de investigação), a qual trouxe novos desafios para alunos e professores.

Nesta direção, o professor Kadu partilhou suas impressões sobre as ações dos alunos na realização da tarefa proposta na aula de investigação, argumentando que as principais dificuldades decorrem da falta de familiarização com este tipo de atividade.

[...] esse tipo de atividade [se referindo à aula de investigação] é algo bem diferente para eles [os alunos]. Eu tinha sim, um medo de como a turma ia se comportar, porque o perfil deles [dos alunos] é bem assim, de conversar bastante [...]. Hoje, estavam calmos até, estavam bem tranquilos. [...]. [...]. A té o ano passado e nesse início de ano, dar aula para eles tinha que levar meio assim, não podia dar muito espaço [para conversa] [...]. [...]. [...] tem [alguns alunos] que tem bastante dificuldade e, [outros] que vão e fazem rápido as [atividades], pensam, criam estratégias, meios ali [para resolver as questões] e outros ficam ali [sem saber como fazer], você tem que ficar perguntando [instigando]. Eles [os alunos] não têm iniciativa. É uma turma [com] opostos. Mas, assim, eu gostei da participação deles [na aula de investigação], me surpreenderam (Kadu, transcrição áudio 'sessão de reflexão 2', dezembro de 2019).

Os professores que assumiram o papel de observadores durante a lecionação da aula de investigação partilharam suas impressões e percepções sobre esta experiência (observar as ações aos alunos e depois tentar compreendê-las). Eles ressaltaram aspectos que consideraram marcantes na aula de investigação, conforme excertos a seguir:

Eu estava muito ansiosa. [...] eles [os alunos] não conseguiam [resolver as atividades], [...] não fizeram nada [na primeira aula], nem a primeira questão. [...] e [na segunda aula] eles [os alunos] deslancharam [tiveram mais facilidade em responder as questões] (Judy, transcrição áudio 'sessão de reflexão 1', dezembro de 2019).

[Os alunos] ficaram muito ansiosos com nós [observando]. As meninas [as alunas], com aquelas peças [do tangram], viravam [para um lado] e viravam [para o outro lado], pegavam as quatro [peças do tangram] ou elas [as alunas] pegavam todas [as peças] e não conseguiam montar [figuras]. [...]. Gente, que agonia [só observar e não poder ajudar]. [...]. Mas, [na segunda aula de investigação] eles [os alunos] estavam mais à vontade com nós [...]. Eles [os alunos] estavam tímidos [na primeira aula] (Filipa, transcrição áudio 'sessão de reflexão 2', dezembro de 2019).

De acordo com os professores, tanto àqueles que lecionaram a aula de investigação quanto àqueles que observaram as ações dos alunos, a experiência de observar o trabalho dos alunos constituiu-se em uma experiência nova e distinta em termos das práticas de sala de aula que eles estavam habituados. No início, causou certo 'bloqueio' aos alunos, de modo que sentiram-se desconfortáveis com a presença de um grupo de professores em sala de aula a observar o modo como eles resolviam a tarefa e, por isso, representou um momento de muito aprendizado para todos. A partilha do trabalho em sala de aula oportunizou-os experimentar o papel de investigadores sobre as ações dos alunos, sem intervir nas estratégias e discussões durante o trabalho autônomo deles sobre a tarefa, postura esta que se revelou desafiadora para os professores. Marie partilhou suas impressões sobre este aspecto:

[...] eu senti que no início [da aula de investigação] eles [os alunos] estavam um pouco sem saber como interagir, como ler a proposta, como começar [a resolver as atividades]. Inclusive, o trio, que a gente estava observando, parece que depois que eles voltaram do recreio, daí eles soltaram mais, participaram mais. Realmente, eu acho que a primeira parte [das atividades] foi mais difícil do que a segunda, não sei se porque eles já tinham o jeito do trabalho o quê, mas a segunda deslanchou [avançou] (Marie, transcrição áudio 'sessão de reflexão 2', dezembro de 2019).

As observações de Marie confirmam as impressões de Filipa, quando ela constatou que os alunos não sabiam muito bem como agir no início da aula. Mas, na segunda parte da aula, (após o intervalo) os alunos estavam mais à vontade. Esse aspecto indica que, embora o primeiro momento da aula de investigação seja marcado por certo estranhamento, a dinâmica da aula favorece o envolvimento dos alunos e essa dificuldade logo é superada.

Diálogo. A análise mostrou que o diálogo, aspecto estruturante da colaboração profissional, permeou as etapas do estudo de aula, estabelecendo uma relação mais próxima entre os participantes e, assim, fortalecendo a comunicação entre eles. As narrativas dos professores revelaram que a dinâmica do estudo de aula fomentou a participação, a apresentação e argumentação de pontos de vista, estabelecendo a comunicação e interação no grupo.

O estudo de aula promoveu a comunicação entre os professores mediante a constituição de um contexto que valorizava a exposição de pontos de vista e a troca de ideias, conforme relato a seguir:

Foi bem coletivo mesmo [se referindo à colaboração entre os professores], com a participação de todos [os envolvidos]. Ou concordavam ou discordavam, mas todos foram ouvidos. As opiniões, todas foram valorizadas. Não teve, [por exemplo], a minha ideia vai prevalecer ou a tua [ideia], não houve isso. Houve uma troca de ideias, realmente. [...]. Você colocava [explicitava] a tua opinião, o outro [professor] colocava a outra [opinião], e no final a gente [se referindo ao grupo de professores participantes] chegava num consenso para ver qual seria a melhor alternativa (Judy, transcrição áudio entrevista, julho de 2020).

Judy avalia que o diálogo entre eles se efetivou como uma forma de valorizar a opinião e a experiência de todos, as quais permitiram a organização coletiva e a negociação de ideias para se chegar a um objetivo comum (planejamento da aula de investigação). Este aspecto foi evidenciado logo no início do estudo de aula, na etapa de definição do tópico curricular a ser trabalhado na aula de investigação:

Eu acho interessante a geometria. [...] na figura geométrica explorar a questão dos ângulos (Ellie, transcrição áudio $2^{\mathrm{a}}$ sessão, setembro de 2019).

Então começa com os ângulos. Acho mais fácil. Estudo dos ângulos, aí depois, vai para perímetro. Ou vai direto para as figuras [...], o perímetro e área, daí já passa essa parte dos ângulos (Adelle, transcrição áudio $2^{\mathrm{a}}$ sessão, setembro de 2019). 
E trabalha perímetro e área junto? Não ângulos? Então, eu acho que perímetro, área e figuras, que faz tudo em um só. Então, ficamos [com] perímetro e área com figuras geométricas? (Judy, transcrição áudio $2^{\mathrm{a}}$ sessão, setembro de 2019).

Os professores dialogaram sobre o tópico a ser abordado e todos puderam sugerir tópicos e apresentar argumentos para defender suas sugestões. Em relação aos argumentos que permearam o diálogo no grupo, observamos que os professores preocuparam-se em definir o tópico para que este seguisse a sequência de conteúdos do programa curricular no momento da concretização da aula de investigação, a fim de não prejudicar os alunos (Notas de campo, $2^{\circ}$ sessão, setembro de 2019). Além disso, o diálogo favoreceu a relação e o envolvimento dos professores no planejamento da aula.

[Pensamos] que a questão sete [da tarefa sobre perímetro] deve aparecer depois, [logo após] da questão cinco. Que pede para contornar com o fio dourado. Então, a questão cinco pede para fazer o contorno, e a [questão] sete é uma continuação da [questão] cinco (Adelle, transcrição áudio $8^{\mathrm{a}}$ sessão, novembro de 2019).

É, ficou perdida a questão, a gente não entendeu direito. Mas, a [questão] sete dá sequência à questão cinco (Judy, transcrição áudio $8^{\mathrm{a}}$ sessão, novembro de 2019).

É, lembram [se referindo aos colegas do grupo] que eu tinha falado isso para vocês. Não teve a sequência. [...]. A [questão] cinco é [a soma] de cada figura, e a seis é do mosaico todo. [Então], precisa especificar. Porque é para dizer que era só para decorar o mosaico. Entendi. Então, a gente [se referindo ao grupo] precisa especificar que é o contorno. Olha ali, e nós lemos, relemos, e relemos [as questões e ainda precisa de ajustes] (Ellie, transcrição áudio $8^{a}$ sessão, novembro de 2019).

Para Ellie, o olhar criterioso de todos no planejamento da aula de investigação contribuiu de modo a esclarecer e especificar o enunciado da questão para melhor entendimento dos alunos. E isto somente foi possível porque estabeleceram o diálogo no grupo e o respeito à voz e à opinião do outro. Além disso, as decisões acerca do tópico curricular, os recursos e materiais didáticos a serem elaborados e utilizados na aula de investigação foram negociados e refletidos por todos em face ao diálogo.

Da mesma forma, a organização e a estrutura do planejamento da aula de investigação, sobretudo pela sua natureza colaborativa, intensificou o diálogo no grupo.

[...]. Então, no primeiro momento, com os grupos [de alunos] organizados, será distribuído o material que irá compor o mosaico. Cada grupo receberá quatro cartões brancos que formaram cada mosaico. [Aqui], vocês [se referindo aos colegas professores] haviam comentado. Vocês acham que ficou mais claro [esta questão]? Desse jeito? Vocês acham que melhorou? (Ellie, transcrição áudio $8^{\mathrm{a}}$ sessão, novembro de 2019).

Ellie considera que o diálogo fortaleceu o envolvimento, pois a comunicação e a aceitação da opinião de todos levou-os a sentirem-se acolhidos e aceitos no grupo, possibilitando cada professor expor seus pensamentos e experiências profissionais. As contribuições foram acolhidas como contribuições construtivas, a fim de melhorar a tarefa que estava sendo elaborada e o planejamento da aula. Os apontamentos dos pares não foram considerados como críticas ao trabalho desenvolvido (Notas de campo, 8. ${ }^{\text {a }}$ sessão, novembro de 2019), mas como possibilidade de melhoria. Judy relata que a interação entre eles contribuiu para o planejamento da aula de investigação.

[...] acho que foi um ponto bem interessante. [...]. Teve a outra visão, do que poderia ser diferente [no planejamento]. Nós poderíamos melhorar nisso, nós poderíamos melhorar naquilo. Olha, a gente não pensou nisso, esse aspecto não foi discutido. Eu acho que teve a colaboração de todos e esse entendimento de todos (Judy, transcrição áudio entrevista, julho de 2020).

De acordo com Judy, o diálogo contribuiu positivamente no planejamento da aula de investigação porque fomentou diferentes olhares sobre a tarefa. Maggie relata suas impressões acerca do diálogo estabelecido no grupo:

Teve um respeito enorme entre todos [os professores]. Um [professor] estava falando, [o outro] esperava e depois continuava ou então completava [a ideia] o que o colega estava falando [partilhando]. Havia um respeito, e não sei se é a palavra certa, mas havia uma cumplicidade [entre todos]. Questões de sugestões, mas sempre havia um respeito de quando tinha um falando, esperavam falar [expor sua ideia e/ ou sugestão] para depois o outro [expor a sua] [...] (Maggie, transcrição áudio entrevista, julho de 2020).

O diálogo contribuiu para o crescimento do grupo na medida em que fortaleceu a negociação e a cumplicidade entre eles, oportunizando-lhes um espaço para ouvir e ser ouvido. Favoreceu a organização e o planejamento da prática profissional de forma colaborativa e não hierarquizada. A possibilidade de falar e ser ouvido, de ouvir e questionar, de questionar e ser respondido, propiciou um contexto marcado pela comunicação e, especialmente, pela valorização das múltiplas vozes, que potencializou a interação entre eles e, assim, o crescimento pessoal e profissional de todos.

$\mathrm{O}$ apoio e o incentivo mútuo revelaram-se importantes aspectos da colaboração. No estudo de aula estes aspectos manifestaram-se como elementos indissociáveis, pois enquanto o primeiro oferecia condições materiais e pessoais para que as tarefas fossem realizadas, o segundo ampliava essas condições, encorajando os professores a tomarem iniciativas, a correr riscos e a assumirem um novo desafio, ultrapassando o comodismo e as crenças predominantes em suas culturas.

Os professores revelaram a importância desses aspectos no enfrentamento dos desafios diários no âmbito escolar e no desenvolvimento profissional do professor, de modo que o apoio e o incentivo pessoal e profissional fortaleceram as relações entre pares, consolidando um efetivo grupo de trabalho. Esses aspectos promoveram o encorajamento dos professores, especialmente na etapa de concretização da aula.

Para os professores, o estudo de aula favoreceu o apoio $e$ o incentivo entre os pares, à medida que uns incentivam aos outros, sobretudo nas situações de tomada de decisão:

[...] Dire [se referindo a uma professora que era diretora da escola em que lecionava], fala alguma coisa. Ajuda nós 
[a decidir], a senhora também tem anos de carreira, vai lá! (Maggie, transcrição áudio $2^{\mathrm{a}}$ sessão, setembro de 2019).

Povo [se referindo aos professores] temos que decidir o que nós vamos trabalhar. [...] vamos definir os tópicos, depois vamos para o segundo ponto que são as dificuldades [dos alunos] (Judy, transcrição áudio $2^{\mathrm{a}}$ sessão, setembro de 2019).

No contexto da discussão sobre o tópico a ser abordado no estudo de aula, a professora Maggie incentivou a colega, que era diretora da escola naquele ano, encorajando-a a participar da discussão e relatar suas experiências de sala de aula. De maneira similar Judy, numa base de igualdade com os colegas, incentivou-os a participar da discussão e apresentar suas ideias para a decisão conjunta do tópico curricular. Nestes momentos de decisão, os professores ouviram uns aos outros de maneira respeitosa e motivadora, enfatizando a importância de se fortalecerem enquanto grupo. Em face desse ambiente de acolhimento e incentivo, os professores se mostravam solícitos a colaborar para a concretização da aula de investigação e em criar as condições necessárias para a viabilização do próprio estudo de aula.

Quando a gente começou a [planejar a aula de investigação], [...] fazer a parte da digitação, montar o [planejamento], eu disse: deixa que eu faço essa parte [se referindo ao trabalho no computador]. Eu gosto desses negócios da área voltada à tecnologia, a informática e tal. Daí ia lá [no computador] e já começava a fazer essa parte. [...] eles [os colegas professores] demonstravam segurança [em mim]. Aí [no decorrer do planejamento] já me indicavam e [falavam o que era necessário fazer]. Eu acho que eu tomei a frente disso de ir lá e começar a digitar [o planejamento], a pesquisar [o que era necessário]. [...] [todos] os professores discutiam o plano de aula [e eu organizava] e salvava no drive (Kadu, transcrição áudio entrevista, julho de 2020).

Para Kadu, o apoio e o incentivo entre os pares na etapa do planejamento da aula de investigação resultaram na confiança e no encorajamento em assumir determinadas tarefas no trabalho em equipe. Além disso, o apoio e incentivo entre os pares foram evidenciados na medida em que os professores esforçavam-se para ajustar os próprios horários na tentativa de favorecer aqueles que tinham maior dificuldade em adequar os horários ao estudo de aula, especialmente quem estava na docência em sala de aula:

Eu, como não estou em sala de aula, o meu horário é mais flexível. Eu converso com a diretora [e] reponho outro dia. $\mathrm{O}$ problema é quem [se referindo aos demais professores] está em sala de aula, que não tem como sair (Ellie, transcrição $12^{\mathrm{a}}$ sessão, dezembro de 2019).

Eu tenho coordenação de manhã. O meu horário, também eu posso trocar [...] (Judy, transcrição $12^{\mathrm{a}}$ sessão, dezembro de 2019).

Observamos que desde a primeira sessão, quando nos deparamos com a dificuldade de conciliar as agendas e os horários dos professores na definição do cronograma do estudo de aula, especialmente para a aula de investigação, os professores incentivavam-se uns aos outros, sugerindo encaminhamentos que lhes permitiriam ajustar os horários de trabalho com os encontros do estudo de aula.

Portanto, o apoio e incentivo mútuo estabelecido entre os professores, além de contribuir com iniciativas de condições pessoais para que todos participassem do estudo de aula, favoreceram o enfrentamento dos desafios, medos, receios, angústias especialmente na aula de investigação. Judy destaca que o estudo de aula estabeleceu uma base de apoio e incentivo profissional entre os professores:

Teve muito apoio [entre os professores]. [...]. De ver que a realidade é a mesma, de poder contar para eles [se referindo aos colegas professores], de poder ser ouvido. Todos foram ouvidos. Nós [professores] conseguimos compartilhar [se refere à partilha de ideias, experiências, conhecimentos], nós conseguimos conversar, nós conseguimos dividiros problemas, encontrar melhores soluções. Esse compartilhamento, esse coletivo, essa conversa, esse entrosamento, eu para mim foi bem interessante (Judy, transcrição áudio entrevista, julho de 2020).

De acordo com Judy, o apoio e o incentivo mútuo estabeleceram a confiança entre os pares, contribuindo para o crescimento profissional de todos, possibilitando-lhes encontrar soluções possíveis para os desafios nos processos de ensino e aprendizagem em Matemática. De maneira similar, Ellie reflete sobre a importância do apoio e incentivo dos colegas no enfrentamento dos desafios profissionais:

[...] precisamos desse apoio [...] a gente vê que os problemas que nós enfrentamos lá na nossa escola, não são só nossos. É no geral isso. [...]. Então, nós vemos que não é assim, só na minha escola, e que há muitos desafios, e superando esses desafios é que nós vamos tornar essa prática diária diferente (Ellie, transcrição áudio $3^{\mathrm{a}}$ sessão, setembro de 2019).

Para Ellie, um dos desafios dos professores está em trabalhar a partir das dificuldades dos alunos e, na sua visão, a superação destes desafios solicita o envolvimento colaborativo entre os professores que atuam na mesma área de conhecimento, sobretudo no trabalho conjunto e no apoio que se estabelece no grupo.

Desse modo, o apoio e o incentivo entre pares contribuíram para que os professores superassem dificuldades profissionais cotidianas, oportunizando-lhes constituir um grupo colaborativo, a ter um novo olhar para o trabalho em sala de aula, conforme excerto a seguir:

[O estudo de aula] serviu para dar um gás [um ânimo] na nossa aula porque a gente acaba estacionando [se referindo ao comodismo]. Mesmo no atropelo [na correria] do dia a dia, às vezes, você [professor] até tem vontade, você vai e pesquisa. Mas, se tu não tens um grupo [de professores] te dando corda [apoio] e trocando ideia todo dia, não se alimenta [essa vontade]. Então, isso também foi um ponto super positivo [no estudo de aula], o fato de nós [professores] estarmos toda semana em contato, um conversando e apoiando o outro, incentiva mais a gente a trabalhar (Marie, transcrição áudio entrevista, julho de 2020).

A professora Marie relata que o apoio e o incentivo que havia no grupo de professores contribuíram para sua prática, sobretudo na busca de novos conhecimentos e estratégias de ensino para enfrentar os desafios diários no trabalho em sala de aula. Judy pontua que o apoio e incentivo estabelecido entre os pares contribuíram para que ela superasse algumas inseguranças pessoais e profissionais: 
[...] às vezes, a gente se sente tão inferior [porque] parece que não consegue atingir o aluno, parece que você [enquanto professor] não consegue solucionar tal problema, e ali [no estudo de aula] teve esse apoio. [Os professores partilhavam suas realidades:] olha, eu também vivi essa situação. [...]. Então, acho que esse apoio me fez ser bem mais confiante no meu trabalho e ter um olhar diferente, muitas vezes, para o aluno (Judy, transcrição áudio entrevista, julho de 2020).

De acordo com Judy, conhecer a realidade de outros professores e receber o apoio e incentivo dos colegas levou-a a sentir-se mais capaz e autoconfiante no trabalho que desenvolve em sala de aula porque constatou que suas inquietações e a busca por novas práticas para dirimir as dificuldades dos alunos foram apoiadas e valorizadas no grupo.

\section{Discussão}

A dinâmica de desenvolvimento do estudo de aula oportunizou aos professores vivenciar uma experiência profissional baseada na colaboração (Hargreaves, 1998; Puchner e Taylor, 2006), distinta das atividades formativas frequentemente desenvolvidas nas redes de ensino da região (Richit, Ponte \& Tomkelski, 2020).

A colaboração concretizou-se mediante a partilha de experiências profissionais e objetivos educacionais, oportunizando aos professores discutir as dificuldades dos alunos no tópico curricular abordado no estudo de aula (Ponte et al., 2014; Richit \& Ponte, 2019), a propor novas estratégias, recursos e tarefas para a aula de investigação (Ponte et al., 2016; Araujo, Ribeiro \& Fiorentini, 2017) e a observar os alunos (Puchner \& Taylor, 2006). Além disso, as sugestões e relatos partilhados pelos pares foram valorizados e tomados como ponto de partida no planejamento da aula e na criação de recursos adequados para aquele tópico em face às características da turma e da escola.

As situações em que os professores puderam partilhar suas angústias e inseguranças (Lima, 2002; Borges, 2007) se constituíram em contexto de aprendizagens profissionais (Day, 1999; Ponte et al., 2016; Richit \& Tomkelski, 2020) e de fortalecimento do grupo (Borges, 2007), favorecendo o desenvolvimento profissional dos participantes (Fiorentini, 2008). Perceberam que compartilhavam o receio de experimentar uma prática de sala de aula diferente (a aula de investigação), o qual trouxe novos desafios para alunos e professores (Richit \& Ponte, 2019; Richit, 2020). A partilha de sentimentos (anseios, angústias, medos...) levou os professores a se sentirem parte de um grupo que partilha vivências, sentimentos e expectativas (Nóvoa, 1995). Assim, sentiram-se fortes e encorajados a vencer o constrangimento de aceitar as próprias dificuldades e a engajar-se no processo.

A colaboração, centrada no trabalho dialogado, negociado e refletido, no qual os professores partilham objetivos e experiências (Hargreaves, 1998; Lima, 2002; Borges, 2007), foi potencializada pela partilha do trabalho em sala de aula, levando-os a experimentar uma importante mudança em termos do papel assumido pelo professor em sala de aula: observar os alunos (Cajkler, Wood, Norton \& Pedder, 2014) e compreender as suas estratégias e dificuldades (Ponte et al., 2014, Richit \& Tomkelski, 2020). Essa experiência os oportunizou experimentar o papel de investigadores sobre as ações e aprendizagens dos alunos mediante a proposição de uma tarefa elaborada para tratar dificuldades de aprendizagens específicas sobre aquele tópico curricular.

Assim, o estudo de aula, pela sua natureza colaborativa, se constituiu em um contexto para promover o desenvolvimento profissional (Ponte, Quaresma, Mata-Pereira \& Baptista, 2016; Fiorentini, 2008), contribuindo para a aprendizagem dos alunos (Puchner \& Taylor, 2006) e para produzir tensões na cultura do isolamento, predominante na atividade docente (Richit, Ponte, \& Tomkelski, 2020). Desta forma, apontou a possibilidade de acrescentar novas características e práticas à cultura profissional dos professores, cujas rotinas, no interior e no exterior da profissão, são marcadas por intensas interações e partilhas (Nóvoa, 1995; Hargreaves, 1998, Lima 2002, Borges, 2007, Nóvoa, 2009;).

O diálogo constitui-se em um contexto de confronto de ideias e de construção de novas compreensões (Goulet, Krentz \& Chistiansen, 2003), na medida em que a comunicação e a interação entre os professores constituíram-se em elementos basilares no trabalho em grupo. O diálogo revelou-se fundamental para a efetiva concretização da colaboração na medida em que as vozes eram ouvidas, aceitas e se entrelaçavam, favorecendo a consciência de que nenhuma ideia, nenhuma proposição era definitiva (Goulet, Krentz \& Chistiansen, 2003).

$\mathrm{O}$ encorajamento para que as vozes individuais fossem externalizadas no grupo e valorizadas pelos pares (Goulet, Krentz \& Chistiansen, 2003) contribuiu para que o diálogo se intensificasse na medida em que cada professor se envolvia no processo. Assim, níveis mais elevados de comunicação se estabeleciam entre os pares e se estendiam para outros momentos e contextos, transcendendo as interlocuções das sessões do estudo de aula (Richit \& Ponte, 2019).

Por fim, o diálogo no estudo de aula, concretizado mediante a interação entre os pares, revelou marcas das culturas profissionais (Hargreaves, 1998, Thurler, 2001, Lima, 2002, Borges, 2007) predominantes nas escolas. Observamos que a interação é uma característica do trabalho docente escolar, mas que, na maioria das vezes, se limita à interação social e partilha de recursos e materiais de ensino. No estudo de aula, por outro lado, os professores puderam ampliar a interação entre pares para a dimensão do planejamento de aula de investigação e para a organização e lecionação da aula.

Além disso, a colaboração concretizou-se devido à dinâmica do estudo de aula que forneceu apoio mútuo (Hargreaves, 1998; Fialho \& Sarroeira, 2012), promovendo o comprometimento dos participantes no processo ao desenvolverem objetivos comuns. $O$ encorajamento e a confiança que se estabeleceram no grupo os levaram a alcançar 
tais objetivos, beneficiando a todos os envolvidos (Boavida \& Ponte, 2002; Lima, 2002), na medida em que puderam experimentar uma nova prática e trabalhar colaborativamente no planejamento de uma aula diferente para o tópico 'área e perímetro'.

$\mathrm{O}$ apoio e incentivo pessoal, que fortaleceram a confiança entre os pares, motivaram cada participante a envolver-se na dinâmica do estudo de aula (Richit \& Ponte, 2019, Richit, Ponte \& Tomkelski, 2020). Esse aspecto emergiu quando os participantes criaram condições para que todos pudessem participar do processo, ajustando seus horários de trabalho, visando favorecer aqueles que tinham dificuldade de horário.

Além disso, o apoio e o incentivo profissional favoreceram o trabalho em equipe (Richit \& Ponte, 2019) na medida em que juntos buscaram condições para a viabilização do estudo de aula e da concretização das atividades (Tomasi, 2020). A confiança estabelecida mediante o apoio, incentivo e respeito mútuo criaram condições para que os professores expusessem seus pensamentos (Boavida \& Ponte, 2002), ampliassem seus conhecimentos em tópicos específicos (Ponte et al., 2014) e, sobretudo, enfrentassem e superassem suas crenças, dúvidas e dificuldades. O encorajamento promovido pelo apoio e incentivo entre os pares possibilitou um novo olhar sobre a prática, motivando mudanças (Hargreaves, 1998; Ponte et al, 2014; Araújo, Ribeiro \& Fiorentini, 2017), favorecendo o crescimento pessoal e profissional dos participantes (Nóvoa 1995, Nóvoa, 2007, Richit \& Ponte, 2019).

Por fim, a partilha, o diálogo e o apoio entre os professores (Boavida \& Ponte, 2002; Lima, 2002; Borges, 2007) favoreceu a superação de dificuldades dos alunos (Ponte et al., 2014) e pontos de vista dos professores. A confiança, favorecida pelo apoio e incentivo mútuo, foi essencial para consolidar a colaboração no grupo.

\section{Conclusão}

A análise evidenciou que a participação dos professores no estudo de aula os levou a experimentar o papel de investigadores sobre as ações dos alunos e suas aprendizagens, a fim de compreender suas estratégias e dificuldades, propondo uma prática que os ajudasse a superar essas dificuldades. Além disso, as narrativas explicitaram suas experiências profissionais, as quais favoreceram a partilha e a reflexão acerca das possibilidades e desafios no ensino de matemática em sala de aula. Na medida em que os professores se envolviam nas etapas do estudo de aula, as contribuições tornavam-se fundamentais para o desenvolvimento do processo, o que os levou a valorizar a partilha, o diálogo, o apoio e incentivo mútuo como formas de promoverem o próprio desenvolvimento profissional.

A partilha concretizou-se à medida que os professores participantes interagiam e partilhavam experiências profissionais e objetivos educacionais. $\mathrm{Na}$ socialização de experiências, estratégias e materiais de ensino, os professores tiveram a oportunidade de aprimorar os conhecimentos acerca do tópico 'área e perímetro'. Além disso, a partilha de sentimentos (anseios, angústias, medos...) fortaleceu o envolvimento no processo, levando-os a sentirem-se acolhidos no grupo.

O diálogo favoreceu a interação entre os professores e consolidou a comunicação no grupo. O diálogo valorizou as múltiplas vozes, contribuindo para a construção de novas compreensões e a aceitação da opinião do outro, pois os professores sentiram-se acolhidos e valorizados no grupo. Além disso, possibilitou ampliar a interação entre os pares, especialmente entre os colegas professores que ensinam matemática nas distintas escolas da região, favorecendo o diálogo em diferentes etapas do processo de negociação de decisões, transpondo os limites do estudo de aula.

$\mathrm{O}$ apoio e o incentivo mútuo contribuíram para o enfrentamento dos desafios diários na rotina escola, bem como no desenvolvimento do trabalho em equipe. $\mathrm{O}$ apoio e o incentivo estabeleceram a confiança no grupo, de modo que cada participante sentiu-se motivado a envolver-se no processo e, sobretudo, a enfrentar e superar crenças e dificuldades pessoais e/ou profissionais. Favoreceram, também, o crescimento pessoal e profissional dos participantes, pois os encorajaram a revelar os desafios de sala de aula e a buscar, juntos, alternativas para esses desafios.

Em síntese, o estudo de aula, concebido como uma abordagem de desenvolvimento profissional de professores centrada na colaboração e na reflexão, favoreceu as relações entre os participantes, despertando o sentimento de pertença a um grupo que enfrenta desafios similares e compartilha objetivos educacionais. A dinâmica do estudo de aula promoveu a partilha de ideias e experiências, o diálogo, o apoio e incentivo mútuo entre os professores e esses elementos fortaleceram as ações e interações entre os professores participantes e a confiança entre os pares. Ademais, essa experiência contribuiu para o desenvolvimento profissional, pois oportunizou aos professores aprimorar seus conhecimentos acerca de um tópico específico da matemática (área e perímetro), bem como nas estratégias de ensino que resultaram em aprendizagens profissionais.

\section{Agradecimentos}

Agradecemos ao aos professores participantes do estudo de aula, que contribuíram para a realização deste trabalho-Arlete, Cesar, Elis, Fabiana, Jossandra, Jucilei, Maríndia e Maritânia. Agradecemos também ao CNPq pelo financiamento a nossa pesquisa (Processo: 305476/2020-3).

\section{Referências}

Araujo, W. R., Ribeiro, M., \& Fiorentini, D. (2017). Lesson study no grupo de sábado: o prelúdio de uma tarefa desenvolvida no subgrupo do Ensino Médio. Anais do $7^{\circ}$ Congresso Internacional de Ensino da Matemática, Canoas, Brasil.

Boavida, A.M., \& Ponte, J.P. (2002). Investigação colaborativa: Potencialidades e problemas. In GTI (Org.). Reflectir $e$ investigar sobre a prática profissional (pp. 43-55). Lisboa: 
APM.

Borges, M.P.A. (2007). Professores: Imagens e auto-imagens (Doctoral dissertation in Education, Universidade de Lisboa, Faculdade de Ciências).

Cajkler, W., Wood, P., Norton, J., \& Pedder, D. (2014). Lesson study as a vehicle for collaborative teacher learning in a secondary school. Professional Development in Education, 40(4), 511-529.

Day, C. (1999). Developing teachers: The challenges of lifelong learning. London: Falmer.

Denzin, N.K., Lincoln, Y.S. (2006). O planejamento da pesquisa qualitativa: teorias e abordagens. Porto Alegre: Artmed.

Fialho, I., \& Sarroeira, L. (2012). Cultura profissional dos professores numa escola em mudança. Educação: Temas e problemas, Évora, 9, 1-20.

Fiorentini, D. (2008). A pesquisa e as práticas de formação de professores de Matemática em face das políticas públicas no Brasil. Boletim de Educação Matemática, 21(29), 43-70.

Goulet, L., Krentz, C., \& Christiansen, H. (2003). Collaboration in Education: The Phenomenon and Process of Working Together. The Alberta Journal of Educational Rese, 49 (4), 325-340.

Guskey, T. (2002). Professional development and teacher change. Teachers and Teaching: Theory and Practice, 8(3/4), 381391.

Hargreaves, A. (1998). Os professores em tempos de mudança. Lisboa: McGraw-Hill.

Lewis, C. (2002). Lesson study: A handbook of teacher-led instructional change. Philadelphia, PE: Research for Better Schools.

Lima, J.A. (2002). Culturas colaborativas nas escolas: Estruturas, processos e conteúdos. Porto: Porto Editora.

Nóvoa, A. (1995). Profissão professor. Porto Alegre: Porto.

Nóvoa, A. (2007). O regresso dos professores. In: Conferência Desenvolvimento profissional de professores para a qualidade e para a equidade da Aprendizagem ao longo da vida. Lisboa: Ministério da Educação.

Nóvoa, A. (2009). Professores, imagens do futuro presente. Lisboa: EDUCA.

Ponte, J. P. (1995). Perspectivas de desenvolvimento profissional de professores de Matemática. In: J.P. Ponte; C. Monteiro; M. Maia; L. Serrazina \& C. Loureiro (Org.). Desenvolvimento profissional de professores de Matemática: Que formação? (pp. 193-211). Lisboa: SEM-SPCE.

Ponte, J. P. (1998). Da formação ao desenvolvimento profissional. In: Actas do ProfMat 98. Lisboa: APM. 27-44.

Ponte, J.P., Quaresma, M., Mata-Pereira, J., \& Baptista, M.
(2016). O estudo de aula como processo de desenvolvimento profissional de professores de matemática. Boletim de Educação Matemática, 30(56), 868-891.

Ponte, J.P., Quaresma, M., Mata-Pereira, J., \& Baptista, M. (2014). Os estudos de aula como processo colaborativo e reflexivo de desenvolvimento profissional. In: J. Sousa \& I. Cevallos. (Org.). A formação, os saberes e os desafios do professor que ensina matemática (pp. 61-82). Curitiba: Editora CRV.

Puchner, L. D. \& Taylor, A. R. (2006). Lesson study, collaboration and teacher efficacy: Stories from two school-based math lesson study groups. Teaching and Teacher Education, 22(7), 922-934.

Richit, A. (2020). Estudos de aula na perspectiva de professores formadores. Revista Brasileira de Educação, 25.

Richit, A \& Ponte, J. P. (2020). Conhecimentos profissionais evidenciados em estudos de aula na perspectiva de professores participantes. Educação em Revista. Belo Horizonte. 36, $1-29$.

Richit, A \& Ponte, J. P. (2019). A colaboração profissional em estudos de aula na perspectiva de professores participantes. Bolema, 33(64), 937-962.

Richit, A \& Ponte, J. P. (2017). La Colaboración Docente en Estudios de Clase en la Perspectiva de Professores Participantes. Revista Paradigma, XXXVIII, 1, 330-352.

Richit, A., Ponte, J. P., \& Tomkelski, M. L. (2020). Desenvolvimento da prática colaborativa com professoras dos anos iniciais em um estudo de aula. Educar em Revista, $36,1-24$.

Richit, A., Ponte, J. P., \& Tomkelski, M. L. (2019). Estudos de aula na formação de professores de matemática do ensino médio. Revista Brasileira Estudos Pedagógicos, 100 (254), 54-81.

Richit, A., Ponte, J. P., \& Tomasi, A. P. (2021). Aspects of Professional Collaboration in a Lesson Study. International Electronic Journal of Mathematics Education, 16(2).

Richit, A. \& Tomkelski, M. L. (2020). Aprendizagens Profissionais de Professores de Matemática do Ensino Médio no Contexto dos Estudos de Aula. Acta Scientiae - Revista de Ensino de Ciências e Matemática, 22(3), 2-27.

Saraiva, M., \& Ponte, J.P. (2003). O trabalho colaborativo e o desenvolvimento profissional do professor de Matemática. Quadrante, 12(2), 25-52.

Thurler, M.G. (2001). Inovar no interior da escola. Porto Alegre: Artmed.

Tomasi, A. P. (2020). Aspectos da colaboração profissional docente mobilizados em um estudo de aula no contexto brasileiro. Mestrado em Educação, Universidade Federal da Fronteira Sul, Chapecó, Brasil. 